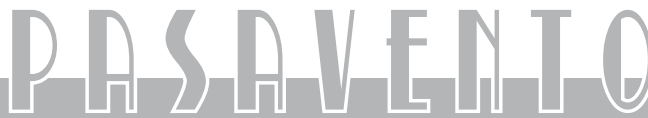

Revista de Estudios Hispánicos

Vol. I, n. 2 (verano 2013), pp. 369-379, ISSN: 2255-4505

\section{"EL ARGUMENTO GENERAL DE MI POESÍA ES EL LENGUAJE". ENTREVISTA A JOSÉ MANUEL CABALLERO BONALD}

\author{
JUAN JOSÉ LANZ \\ Universidad del País Vasco-EHU \\ Juan Carlos Abril \\ Universidad de Granada
}

Juan José Lanz y Juan Carlos Abril: Nos gustaría empezar esta entrevista hablando de sus dos últimos libros publicados: Oficio de lector (Barcelona, Seix Barral, 2013) y Entreguerras (Barcelona, Seix Barral, 2012). El primero es una recapitulación de artículos, prólogos y conferencias sobre diversos autores-lecturas de libros, los denomina-, publicados a lo largo de más de cincuenta años; el segundo es uno de los libros de poesía más tremendos y conmovedores que se han publicado en los últimos años. Comenzaremos hablando de Oficio de lector. En una entrevista reciente, usted declaraba: "Yo me hice escritor porque leí primero a unos escritores que me emocionaron". ¿Debemos entender, por lo tanto, que Oficio de lector traza una particular historia de la literatura española, aunque también en otras lenguas, de José Manuel Caballero Bonald?

José Manuel Caballero Bonald: Sí, en cierto modo sí. Por ahí andan muchos de los poetas y narradores que me han favorecido con alguna recompensa placentera como lector, aparte de afectar de uno u otro modo a mi propio concepto de la literatura como obra de arte. Pero también hay casos de escritores a los que leí con gusto hace años y que, releídos al cabo del tiempo, me han decepcionado. $O$ sea, que este libro mío tiene mucho de canon personal de la literatura en lengua española, dicho sea con la debida prudencia.

JJL y JCA: Todo escritor, toda generación-como planteaba T. S. Eliot- reescribe la tradición, actualiza unos nombres y posterga otros, retoma aspectos olvidados de unas obras y obtura otros que parecían evidentes a las generaciones anteriores. Si 
es así, Oficio de lector ofrece una guía muy especial de las preferencias de su autor, pero también hace evidentes las huellas en su obra. Porque, sí, están los autores del canon español (Cervantes, San Juan de la Cruz, Góngora, Quevedo, Cadalso, etc.), pero son sintomáticos los aspectos de su escritura sobre los que se llama la atención: la "poesía crítica" de Quevedo, el barroquismo de Góngora, la "imaginación romántica" de Espronceda, o "las inciertas fronteras de la realidad" en Bécquer, entre otras. Por no hablar de los autores contemporáneos, donde, de nuevo, junto a autores "canónicos" (Juan Ramón Jiménez, Antonio Machado, los poetas del 27, Neruda, Blas de Otero, Valente, etc.), aparecen otros quizás menos consensuados, como Olga Orozco, Pedro Pérez-Clotet, Álvaro Cunqueiro, Carlos Edmundo de Ory, Pablo García Baena, Eduardo Cote, Manuel Padorno o Alfonso Grosso, todos ellos autores fundamentales, desde nuestro punto de vista, pero no siempre avalados por el consenso canónico. ¿Qué aportan estos autores a la historia literaria en nuestra lengua? ¿Qué añaden al canon literario en español y qué aportan a la obra de Caballero Bonald?

$J M C B$ : Comparto el juicio de Eliot sobre esa tendencia generacional a reescribir la propia tradición. Más que de reescribir, yo hablaría de actualizar la tradición, de expurgarla, de restaurar lo más aprovechable de ella. A mí, como a todos los escritores que basan fundamentalmente su obra en el lenguaje, que entienden la literatura como una construcción verbal, el realismo se me va quedando cada vez más relegado a un plano secundario. Yo creo que eso se nota en Oficio de lector. Mis predilecciones abarcan un eje que va de Góngora a Juan Ramón Jiménez, se prolonga hasta César Vallejo, Carpentier, Onetti, Lezama, Rulfo, y llega luego hasta Cunqueiro, Ory, Valente, Barral... Esos son los protagonistas de mi historia de lector, pero también mis modelos literarios predilectos. Por ahí anda la imaginación traspasando la barrera de lo real. Ya se sabe que la auténtica literatura no copia, no reproduce la realidad, sino que la interpreta, la reinventa por medio del lenguaje.

JUL y JCA: Entreguerras es, en cierto modo, una crónica vital alucinada, a mitad de camino entre el testimonio directo y la imagen de corte irracional que irrumpe en el texto para darnos otra perspectiva; entre el barroco y el surrealismo. También es un "libro total", en la órbita de lo que pudiera ser Espacio, de Juan Ramón Jiménez, o Piedra de sol, de Octavio Paz. ¿Hasta qué punto el libro indaga en una línea que trata de mostrar la contrafaz de la imagen consensuada de la realidad, una contrafaz que se construye en el diálogo de la memoria con el lenguaje, y que huye de la dimensión racional del realismo? ¿Puede verse Entreguerras como el reverso poético de La novela de la memoria, en que el lenguaje poético se siente liberado de la anécdota puntual para indagar en una dimensión diferente que no se podía tratar en los libros de memorias? Aunque quizás llamarla "autobiografía en verso" sea exagerado, tal vez trata de abrir un camino nuevo en esa dirección, ¿no es así?

JMCB: Lo de "autobiografía en verso" no es un apelativo acertado, no encaja muy bien en el libro... Entreguerras es otra cosa, su planteamiento se acerca más a esa 
idea del "reverso poético" de unas memorias, ese irracionalismo de fondo que se desentiende del realismo y basa en el lenguaje su esencialidad expresiva. Yo concebí ese libro de una forma súbita, como a fogonazos, y lo escribí a rachas torrenciales, un largo y a veces hermético soliloquio al que se iban incorporando fragmentos de memorias, hechos vividos, libros leídos, viajes, amores, desamores, yo qué sé... Me siento muy bien expresado en ese libro. Ahí está todo lo que me quedaba por decir. Y ahí está la manera como quería decirlo.

JJL y JCA: Sin duda, llama la atención que alguien, a una edad avanzada, siga manteniendo el tesón y el compromiso con la lucha social y ciudadana. En unas declaraciones recientes señalaba que el escritor "debe ser un vigilante del poder, de cualquier poder", y ha de colaborar en "la regeneración moral y cultural de la sociedad". A muchos despistados, que no hubieran sabido percibir el latido cívico de su poesía o que pensaran que este ya se habría amortiguado con el tiempo, seguramente les sorprendería la aparición de Manual de infractores (2005) y de La noche no tiene paredes (2009). Ambos manifiestan un semejante espíritu de indignación contra la realidad circundante 0 , por decirlo con sus palabras, "una crisis de indignación ante ciertas atrocidades que ocurrían por ahí y frente a la "pasividad general que me irrita". ¿Cuál debe ser la función social del poeta hoy en día? ¿Debe el poema mostrar el hallazgo de una nueva verdad o sembrar la sospecha en el lenguaje contra cualquier discurso dogmático? Cuando dicen que el compromiso social del escritor puede tener ya algo "de trasnochado, de anacrónico", ¿usted qué piensa?

$J M C B$ : Siempre he pensado que el escritor debe ser la "conciencia vigilante" de la sociedad, un testigo crítico del poder, sea del signo que sea. Pero eso no significa que su obra deba responder literalmente a esa actitud. La moral del escritor debe trascender su propia obra. Yo entiendo perfectamente que la escritura no obedezca a más razón que a la estrictamente estética, y que el autor, como individuo, intervenga de un modo directo y personal en la historia. Pienso además que el escritor trasvasará siempre a su obra, aun sin proponérselo, su propia ideología, pero esa ideología no debe ser en ningún caso una imposición previa a la obra. O sea, que estoy de acuerdo con que el compromiso del escritor, en tanto que profesional de la literatura, se centre en el trabajo indagatorio en su propia obra, y que, como miembro de una sociedad, actúe conforme a los dictados de su propio pensamiento crítico, de sus propias inducciones ideológicas.

JL y JCA: En unas declaraciones a José Batlló publicadas en 1968, usted señalaba: "El acto de escribir supone para mí un trabajo de aproximación crítica al conocimiento de la realidad y también una forma de resistencia frente al medio que me condiciona". ¿Podríamos decir que lo fundamental de su poética radica justamente en la proyección de un elemento en otro; es decir, la búsqueda del conocimiento como una forma de resistencia, manifiesta en la desconfianza ante las verdades establecidas? 
JMCB: Las verdades establecidas son todas sospechosas de algo... Mi poética está situada, o yo quiero verla situada, entre el romanticismo y el surrealismo, que no son credos tan distintos como parece. Yo trabajo con el lenguaje, me esfuerzo para que sea el lenguaje con su propia potencia el que penetre por detrás de la realidad y alumbre un mundo desconocido. Pretendo aproximarme así a la iluminación que proporciona toda poesía verdadera, ese conocimiento que se va generando a medida que se escribe un poema, esas palabras que, como me gusta reiterar, significan más de lo que significan en los diccionarios. El argumento general de mi poesía, o de los últimos tramos de mi poesía, es el lenguaje. Por ahí he andado abriéndome paso...

JL y JCA: Por otro lado, en los Encuentros con el 50 celebrados en Oviedo en 1987, subrayaba que en su generación "hubo un momento en que nos sentimos estimulados a usar la literatura como un vehículo de ideas políticas, o morales en un sentido más estricto". Y en declaraciones a Rubén Vela para su antología Ocho poetas españoles (1965), señalaba que la función de la poesía debería estar "ligada a la responsabilidad del poeta con su tiempo". ¿Cómo ha ido evolucionando esta postura estética y moral en su poesía? ¿Qué matices adquiere el compromiso ético en sus libros de poemas desde entonces? No hace mucho tiempo, declaraba que "la literatura es una versión de la realidad, no su reflejo", ¿hasta qué punto contraviene esa perspectiva el modelo adoptado en aquellos años de lucha política?

$J M C B$ : Eso de la responsabilidad del poeta con su tiempo es una cuestión bastante compleja. Sin duda que hay momentos en la historia de un país, en el eco de esa historia en la vida personal, en que resulta inevitable, moralmente inevitable, tomar partido incluso con los instrumentos de la propia obra. Eso ocurrió entre nosotros en una etapa que va más o menos de mediados de los años cincuenta a mediados de los sesenta. Se adoptó el llamado realismo crítico o social o socialista como la fórmula más adecuada para canalizar también esa lucha con las armas de la literatura. Ese concepto del engagement que nos llegaba entonces de Sartre... Ahí había una manifiesta justificación histórica. Todo estaba condicionado por la política, por la lucha clandestina contra la dictadura. Para qué vamos a hablar de los resultados, que generalmente fueron tan precarios, tan mediocres...

JL y JCA: En la misma antología de Rubén Vela señalaba que se consideraba incluido en la generación "realista", aunque insistía en "señalar la posible diversidad de medios expresivos de algunos de los componentes de dicho grupo". ¿Cuál era esa "diversidad de medios expresivos" y cómo ha ido cambiando a lo largo de estos años? Allí también reivindicaba a Antonio Machado y su Juan de Mairena como "el más íntegro y ejemplar espejo de la última poesía española"; sin embargo, en unas declaraciones recientes apunta que cada vez se siente "más alejado de escritores tan distintos como Unamuno o Baroja, León Felipe o Manuel Machado, y al contrario, cada vez aprecio más a Valle-Inclán, a Juan Ramón Jiménez, a Onetti, a Rulfo, a Lezama". ¿Qué era lo que le atraía de los escritores anteriores y qué le atrae de estos últimos? ¿Hasta qué punto se siente distante hoy de las corrientes realistas 
y cómo valora su contribución a aquel movimiento con Dos días de setiembre (1962), en la narrativa, y Pliegos de cordel (1963), en la poesía? ¿Qué sentido tuvo para usted en aquel momento dicho movimiento y cómo lo ve desde la perspectiva actual?

$J M C B$ : Ya he contestado a algo de todo eso anteriormente. A mí me costó trabajo adecuar mi obra, o un cierto espacio de mi obra, a esa -llamémosla así- responsabilidad moral, a ese tipo de realismo crítico, pero lo hice sin que nadie me exigiera nada. Igual les ocurría a otros compañeros de generación, a Barral, a Valente, a Claudio Rodríguez, a Brines... Pero también había algunos, claro, que se encontraban muy a gusto en esa esfera realista. Decía Barral que a ver cuándo se superaba esa etapa de exigencia moral para que pudiésemos recobrar una manera de entender la literatura que habíamos dejado como hibernada. Y esa superación llegó sin aviso previo, no sé si por cansancio o por exceso o por inoperancia, y cada cual volvió al camino que más a gusto había frecuentado y que se había quedado como en suspenso... Nada de eso se comprende ahora mucho, pero eso fue lo que ocurrió.

JL y JCA: Desde 1960 reside en Bogotá, donde es profesor de literatura española en la Universidad Nacional de Colombia. Alli entra en contacto, a través de Eduardo Cote, a quien ya había tratado en Madrid, con el grupo de la revista Mito, integrado entre otros por Jorge Gaitán Durán, Gabriel García Márquez, Hernando Valencia, Pedro Gómez Valderrama y Fernando Charry Lara. Es cierto que algunos poetas latinoamericanos de su generación habían coincidido en Madrid en los años cincuenta y habían entrado en relación con los poetas españoles más jóvenes, pero ¿qué aportó a su poesía y a su obra en general el contacto directo con la joven literatura colombiana? La crítica ha considerado sus años colombianos como una suerte de exilio, ¿también los considera usted así?

JMCB: Bueno, sí, algo de eso hubo, no descarto esa eventualidad del exilio voluntario... Mi vida, entre Madrid y Palma de Mallorca, por aquellos finales años cincuenta, no era precisamente ni fácil ni cómoda. Fue una etapa muy complicada, muy condicionada por la política, la experiencia sentimental, los ajetreos, las privaciones... Estaba bastante cansado, bastante deprimido... De modo que se me presentó la ocasión de irme a Bogotá a enseñar literatura y no lo dudé ni un momento. Me casé y me fui. Colombia fue una de mis patrias más duraderas, tal vez la más querida después del Coto de Doñana... Además, también pertenezco de algún modo a esa tradición literaria.

JL y JCA: Posteriormente, en los años sesenta viaja varias veces a Cuba, donde también coincidirá con Blas de Otero, que en esos años reside en la isla caribeña. Esa estancia tiene como consecuencia inmediata la antología Narrativa cubana de la Revolución (1968), pero ¿qué otras consecuencias tiene para su obra la estancia en Cuba esos años y el debate estético e ideológico sobre el papel de la literatura y la poesía en la sociedad revolucionaria? 
$J M C B$ : Yo he mantenido siempre con Cuba unas relaciones muy especiales. El hecho de que mi padre fuese cubano, de Camagüey, tuvo desde luego que influir en todo eso. Me sentí muy unido, muy aliado a la revolución cubana triunfante, a lo largo de la década de los sesenta. Anduve por allí en tres ocasiones, y lo pasé muy bien y me relacioné con poetas y novelistas cuyo magisterio no he olvidado: Carpentier, Lezama Lima, Virgilio Piñeira, César López, Fayad Jamis... Luego, a partir de mi última visita, las cosas empezaron a cambiar... La revolución se había atascado en una maraña de dogmatismos y burocracias, y ya yo me fui sintiendo cada vez más alejado, cada vez más crítico... Lo que pasa es que cuando oigo a alguien hablar mal de Cuba, yo acabo defendiéndola quizá por instinto...

JL y JCA: También esos años son años de silencio poético. Desde 1963, en que se publica Pliegos de cordel, hasta la aparición en 1977 de Descrédito del héroe, no publica ningún nuevo libro de poemas. Es significativo ese silencio en unos momentos en que las urgencias sociales seguramente requerían un papel distinto del escritor. ¿Por qué esos años de silencio? Y, sin embargo, para quien creyera entonces que el poeta Caballero Bonald había sido sepultado por el novelista, con Dos días de setiembre (1962) y Ágata ojo de gato (1974), y el folklorista, la aparición de Descrédito del héroe y posteriormente de Laberinto de Fortuna (1984) fue una agradable sorpresa. ¿Qué significaron estos libros en su evolución literaria? ¿Cómo respondían a la situación histórica del momento?

$J M C B$ : He atravesado por más de una larga etapa de silencio, en alguna ocasión de más de diez años... Muchas veces me he preguntado a qué se debían exactamente esos paréntesis. Y creo que se juntaban varias causas: el desconcierto, la necesidad de recapitulación, la actividad política, el hastío... No sé, todo eso junto. De pronto, comencé a darle vueltas a una historia vinculada al Coto de Doñana, que ha sido desde que yo era niño mi paraíso particular... Todo empezó como una reacción defensiva contra los peligros que entonces se acrecentaban en torno a Doñana y pensé en valerme del viejo mito de la mater terrae, de la madre tierra que castiga a todo el que pretende ultrajarla, para montar una historia presunta sobre ese territorio sagrado. Ahí empecé de nuevo... Así nació Ágata, que todavía sigue siendo mi libro predilecto, y así nació, casi al mismo tiempo, Descrédito del héroe, del que arranca un nuevo tramo de mi poesía, una nueva manera de entender el lenguaje de la poesía. De modo que ahora, después de tanto tiempo, pienso que valió la pena haber guardado más de una década de silencio...

JUL y JCA: Descrédito del héroe, de Caballero Bonald; Descripción de la mentira, de Antonio Gamoneda; Primer y último oficio, de Carlos Sahagún; El vuelo de la celebración, de Claudio Rodríguez; Tres lecciones de tinieblas, de José Ángel Valente; Insistencias en Luzbel, de Francisco Brines, entre otros, son libros de autores de su generación con títulos bien significativos, que manifiestan una clara voluntad de análisis y desmantelamiento de las estructuras formales, éticas y educativas del franquismo en los primeros años de la transición, al mismo tiempo que proyectan sus sospechas hacia el nuevo sistema que se está instaurando. Quizás pudieran 
añadirse otros títulos de autores más jóvenes, como Fiesta en la oscuridad, de Diego Jesús Jiménez. Vista con la perspectiva de los años, ¿cuál fue la función de aquellos libros de poemas y qué aportaciones hicieron, desde su punto de vista, a la evolución de la poesía posterior?

$J M C B$ : Sí, ya le digo, tengo la impresión de que Descrédito del héroe fue un libro clave en mi trayecto como poeta. Ese libro lo escribí casi al mismo tiempo que Ágata ojo de gato, y creo que eso se nota bastante. En todo eso había como una ruptura, un desacuerdo con mi obra anterior, con la poética que la había sustentado, más o menos vinculada a veces a un realismo de vuelo rasante. Ahí empecé a abrirme paso por ese concepto de la literatura entendida como un hecho lingüístico...

JL y JCA: Otro lapso de trece años discurre entre la publicación de Laberinto de Fortuna (1984) y Diario de Argónida (1997), que participa de la doble esencia que define el territorio, como espacio de rememoración, pero también como espacio de recreación mítica de un pasado.

$J M C B$ : Bueno, entre estos dos libros de poemas, he publicado alguna novela, algún otro libro de asunto vario, de esos que no suponen en el trayecto de tu obra más que un episodio un poco marginal. Ya se sabe que hay décadas en que no está uno para nada. Debí de atravesar por uno de esos periodos depresivos, de abatimiento, que suelen sobrevenirme de vez en cuando, cuando menos lo espero. Siempre me cogen desprevenido... Pero luego, con el paso del tiempo, se me iba despertando otra vez la memoria, me acordaba de cosas que podían ser reconvertidas en materia poética. Y ahí empezaba de nuevo a probar fortuna.

JUL y JCA: En esos años también se publica Campo de Agramante (1992), que mixtifica la realidad y la ficción, el ámbito de lo vivido y lo soñado. ¿Cuál ha sido el cambio de aquella que podríamos considerar como "memoria de la novela" a la posterior novela de la memoria que constituyen los dos libros de memorias, Tiempo de guerras perdidas (1995) y La costumbre de vivir (2001)? ¿Por qué no ha querido continuar el relato de sus memorias más allá de la muerte de Franco?

$J M C B$ : Vamos a ver... La muerte de Franco es una frontera muy significativa, sobre todo para la gente que, como yo, padeció el franquismo desde la infancia a la madurez, cuarenta años, se dice pronto. Con la muerte de Franco se acaba una historia y comienza otra, un fin de trayecto y un punto de partida. Ese era un buen momento para finalizar un ciclo de las memorias. Luego vino la transición, el difícil camino hacia la democracia, y eso ya es otro cantar. Los seis o siete años que van de 1975 y 1982 fueron años bastante angustiosos. La transición fue un apaño de urgencia, el pacto de una historia sin culpables y todo eso... Mi experiencia de entonces fue muy intrincada, lo pasé bastante mal y, con el tiempo, me costaba trabajo rememorar todo lo que había vivido, de modo que decidí no prolongar las 
memorias. Mejor así. Además, para qué andar sondeando esas zonas de nuestra historia reciente que cada vez me parecen más obscenas...

JL y JCA: Demos un salto hacia el principio, hasta los primeros poemas publicados en la revista gaditana Platero y la obtención del accésit del premio Adonáis con Las adivinaciones. ¿Cuáles eran las posibilidades de un poeta joven a fines de los años cuarenta y comienzos de los cincuenta en una ciudad de provincias? ¿Cómo decide presentarse al Adonáis?

JMCB: Pues no sé si me acuerdo bien de todo eso. Ya desde tan lejos se me van acentuando las sombras, las lagunas... Pero algo está claro: las perspectivas de un poeta joven en la inmediata posguerra, a fines de los años cuarenta y principios de los cincuenta, aislado en un rincón provinciano, eran prácticamente nulas. Yo me presenté al Adonáis porque esa era una de las poquísimas posibilidades, por no decir la única, de publicar un primer libro, de salir a flote. La hostilidad cultural, el clima de la sociedad franquista y nacionalcatólica, eran directamente asfixiantes. No sé cómo pude irme abriendo camino. Por eso, cuando me dieron el accésit del premio Adonáis, pensé que se me abría una puerta y enseguida preparé mi escapada desde Jerez, el consabido salto a Madrid, la inocencia perdida.

JL y JCA: Memorias de poco tiempo (1954), Anteo (1956) y Las horas muertas (1959), que obtiene el premio Boscán, suponen su confirmación como poeta en el panorama español de los años cincuenta. ¿Cómo ve aquellos libros en el contexto de su obra poética y qué cree que aportaron en aquellos momentos? Nos gustaría también que comentara el proceso de reescritura constante de sus poemas en las sucesivas ediciones de su poesía reunida.

$J M C B$ : Eso del proceso de reescritura, de las correcciones de mi poesía a medida que se van reeditando, es una manía imposible de curar, lo admito, no puedo evitarlo... Bueno, ahora ya, a la vejez, he ido desentendiéndome un poco de ese prurito. Ya no me corrijo, me resigno a dar por bueno lo ya publicado. Ya no me queda tiempo ni para corregirme.

JL y JCA: ¿Qué supone su llegada a Madrid? ¿Cuál es la relación con los círculos clandestinos de oposición al franquismo? ¿Volvería a irse a Madrid en 1952? ¿Cree que mereció la pena? ¿Haría suyos esos versos de Luis Cernuda del poema "Peregrino"?

$J M C B$ : Pues no sé... Ese poema de Cernuda se refiere más bien al regreso del exilio, o sea que tiene otras connotaciones. El Madrid de 1952 era una ciudad muy poco acogedora, intransitable en según qué espacios sociales. Tengo muy presentes las penalidades propias de la posguerra: el racionamiento de víveres, las restricciones eléctricas, los recelos, el frío, el hambre y, al otro lado, los jerarcas franquistas de fiesta en los bares de putas de la Gran Vía... Era una sensación bastante insufrible. Pero Madrid para mí es la escapada de un clima provinciano muy difícil de aguan- 
tar. Si me sitúo en aquel tiempo, escaparme a Madrid era lo mejor que podía hacer, lo único razonable, estoy seguro. Mi vida dio un giro. A pesar del ambiente más o menos tenebroso, con las secuelas de la guerra todavía muy presentes, a pesar de la soledad, de la grisalla que lo envolvía todo, yo logré abrirme camino. Trabajé primero con Leopoldo Panero en la Bienal Hispanoamericana de Arte, que fue una experiencia bastante incómoda, $y$, tiempo después, con Camilo José Cela en Papeles de Son Armandans. Unos años de aprendizaje difíciles, bastante conflictivos...

JL y JCA: Su relación con Camilo José Cela fue muy importante en sus primeros años, hasta su viaje a Colombia. Con él trabajó en la elaboración de Papeles de Son Armadans y en la organización de los Coloquios de Formentor en 1959. A día de hoy, y tras tantas polémicas sobre la obra del Premio Nobel, ¿qué cree que sigue mereciendo la pena de su obra, qué novelas cree que han sobrevivido al tiempo?

$J M C B$ : Cela era una persona muy compleja, muy inestable, pasaba sin zonas intermedias de ser un sujeto histriónico y retrógrado a ser una persona bien educada, dialogante... Yo trabajé con gusto en Papeles de Son Armadans y logré canalizar en la revista las corrientes de la literatura del exilio y de los poetas y narradores jóvenes de aquellos años... Cela me dejaba hacer y -justo es decirlo- él mismo compartía de buen grado esas iniciativas. Pero no acabé nunca de entenderlo. Me ocurre como con su obra: hay tramos insufribles, retóricos, miméticos, y otros (muy olvidados, por cierto) de extrema belleza lingüística, de una poética de notable eficiencia: por ejemplo, Mrs. Caldwell habla con su hijo y Oficio de tinieblas. A partir del Premio Nobel, Cela se convirtió en un personaje inexistente, absorbido por los más estúpidos hábitos sociales...

JL y JCA: Cuando era joven publicó algunos cuentos -alguno incluso ganó algún premio- en revistas, de estilo realista, ¿por qué abandonó el género?

$J M C B$ : El cuento, como tal género literario, nunca me tentó lo suficiente. O yo no supe familiarizarme con su técnica. Escribí algunos, creo que cuatro o cinco, pero el tiempo tuvo la deferencia de extraviarlos. Hay uno más reciente, de los tiempos de Ágata ojo de gato, que quizá se salve de la quema. Se llama "Nunca se sabe" y apareció en algunas antologías. Eso fue todo.

JL y JCA: En alguna entrevista de la época declaró que estuvo trabajando en una novela entre Dos días de setiembre (1962) y Ágata ojo de gato (1974) que al final no cuajó o terminó. ¿Cómo quedó ese texto y sobre qué trataba?

$J M C B$ : He soñado más de una vez con esa novela que abandoné. Fue a fines de los 60, una época muy complicada para mí... Quiero recordar que escribí como 40 o 50 páginas, no obedientes a ninguna continuidad narrativa sino a un desarrollo intermitente, salpicado de escenas y escenarios posibles. En el sueño hay una copia en limpio de ese borrador y me doy cuenta de que no quiero ni trabajar 
más en esa novela, que es un disparate... Pero no rompo la copia. La guardo cuidadosamente, cosa que se contradice con la realidad, pues ese borrador lo destruí hace mucho. Y me alegro, porque era como una prolongación realista de Dos días de setiembre, solo que ambientada en el mar. Un día me convencí de que por ahí no iba a ninguna parte, que no valía la pena. Por fortuna, la idea de Ágata ojo de gato, que es la novela mía que prefiero, me empezó a rondar por la cabeza y ya no tardó en materializarse.

JJL y JCA: Sus experiencias con el alcohol y con el mundo del vino han estado, de un modo $u$ otro, reflejadas en algunas de sus novelas. ¿Qué parte hay de ficción y de verdad? De igual manera, en la Generación del 50 se ha hablado mucho del alcohol como elemento de unidad, ¿hasta qué punto era algo cultural?

$J M C B$ : El hecho de beber más de la cuenta, los excesos etílicos, tenían en aquellos años un cierto sentido de rebeldía, como de enfrentamiento a lo establecido, a la norma. Algo parecido a la nocturnidad, que también tenía mucho de rechazo instintivo de los convencionalismos, de los biempensantes. Hubo compañeros de generación que se pasaron... Yo tuve algún tropiezo en el consumo alcohólico, me estaba metiendo en ese laberinto autodestructivo que acabó con la vida de casi todos los poetas del 50. Por esas fechas, por las décadas de los cincuenta y sesenta bebí bastante, sobre todo ginebra y vodka, luego me pasé al vino. Y ahora se me ha destapado una especie de intolerancia etílica de lo más inoportuna, o sea, que la nocturnidad y el vino también se fueron al carajo...

JL y JCA: Hasta qué punto suscribiría los versos del poema "Sobre el imposible oficio de escribir": "Por aquella palabra / de más que dije entonces, trataría / de dar mi vida ahora", echando la vista atrás, ¿esos versos se refieren a lo que usted dijo o a lo que escribió? Y si es a lo que escribió, ¿qué proporción hay en su obra de material desechado y de material que finalmente aprovechó y hoy podemos leer?

JMCB: En la primera edición de mis poesías completas, Vivir para contarlo, que es del 69, creo, verifiqué como una especie de expurgo de mi obra poética, que ya se trasmitió a las ediciones posteriores. No lo he cotejado, pero pienso que a lo mejor me equivoqué en la supresión de poemas. Ya se sabe que el gusto se va modificando de modo natural con los años. Incluso hay repertorios léxicos o formas sintácticas que se usaron un tiempo y no volverías a usar al cabo de los años. Se trata de hábitos comunes y hasta de manías, incluso de manías persecutorias.

JL y JCA: Tal como señala al comienzo de Oficio de lector, el libro se cierra con los escritores de su generación, pero la pregunta salta de inmediato: ¿qué escritores posteriores a su generación habría incluido? ¿Podemos esperar un segundo Oficio de lector con esas lecturas de libros de autores posteriores a su generación? $Y$, por otro lado, ¿a qué escritores, entre sus contemporáneos, se siente estéticamente más próximo? 
JMCB: No, no voy a publicar ningún otro Oficio de lector, qué va... Ahí está ya fijado lo que podría ser un inventario particular de libros memorables... Además, los poetas de los que me siento cerca surgidos con posterioridad a los del 50 no iban a dar ni para un folleto, no pasan de tres o cuatro. Y de poetas españoles de mi edad me quedo con Valente, Gamoneda, Barral... 